\title{
Reconstruction of Pedagogical Education-The Fundamental and the Applied in Teacher Education
}

\author{
Rail Mirvaevich Asadullin ${ }^{1} \&$ Filarit Sharifovich Teregulov ${ }^{1}$ \\ ${ }^{1}$ M. Akmullah Bashkir State Pedagogical University, Russian Federation \\ Correspondence: Rail Mirvaevich Asadullin, M. Akmullah Bashkir State Pedagogical University, 450000 Ufa, \\ Russian Federation.
}

Received: January 15, 2015

Accepted: February 26, 2015 Online Published: May 28, 2015

doi:10.5539/ies.v8n6p204

URL: http://dx.doi.org/10.5539/ies.v8n6p204

\begin{abstract}
Authors propose a new approach for the development of educational sphere, where philosophical categories of fundamental and applied knowledge are considered as two counter processes of reality and pole cognition, between which project-technological activity is carried out. This fact allows to treat any pedagogical project as a compromise decision, middle manifestation between the indicated poles, made by multiple coordinations. Taking into account dual character of education, while performing educational activity it is possible to observe so called «pedagogical swing» to either way, expressed by wide diversity. The principle of necessity and reasonable sufficiency of the categories correlation is based on education and training of the specialists.
\end{abstract}

Keywords: fundamental and applied knowledge, conditions of development, abstract and concrete, educational monosystem

\section{Introduction}

Nowadays strengthening of the requirements to fundamental training of the specialists arises a new tendency for practical orientation of professional education. Complying with the requirements of modern economics and industry this condition sets the question: won't such tendency be performed to the disadvantage of the fundamental component of specialists' training process? In science this issue is usually discussed in the context of theoretical and applied knowledge combination. We also should note that such division of knowledge is only conditional and is connected with the detection of sources and orientation of the development of each subdiscipline. Although these two directions of science development have a lot in common and they have one and the same aim-development of the system of knowledge about the ambient reality and ways of its transformation, they differ in the specific functional purpose. At the same time differences in the organization of knowledge do not create serious obstacles for mutual intellectual upgrading of each of the research directions, as they enrich subjects with various knowledge following their own aims. All differences and similarities as well as interflow of the discussed pedagogical notions in the educational process, show the complexity of the situation regarding pedagogical knowledge. Such situation prevents its rational identification and useful application in the teachers training process. Solution of this problem is playing a principle role in the development of pedagogical education.

Nowadays we can see that studying of pedagogical disciplines in higher professional educational institutions does not significantly differ from studying mathematics and physics. Meanwhile pedagogical knowledge should serve as the instrument for learning the nature and regularities of pedagogical phenomena and creation by future teachers of new pedagogical objects: systems, processes, technologies connected with the bringing up and teaching. Our hypothesis is represented by the determination of the possibility to provide understanding of two types of pedagogical knowledge during training process of teachers. These two types of knowledge are: fundamental-the purpose of which is to study pedagogical reality and applied-aimed at planning and development of different ways of influence on people and collectives in order to improve their education.

\section{Methodology}

In modern literature devoted to the studying of the specificity of fundamental knowledge it is emphasized that fundamental knowledge is always connected with search and detection of new "not aging knowledge" with fundamentally reasonable research methods. They always play a dominant avant-garde role, while the applied 
knowledge plays the role of a "servant" for practical knowledge. Fundamental and applied knowledge are complementary and their interference serves as the basis for the development of scientific knowledge as a whole. Nevertheless this interference is formed not just as vertical connections but also as horizontal, as sequential stages of one and the same activity, located in accordance with the principle "from abstract to concrete".

As it is known the concrete is defined as a composite, complex, multiple, as «unity and diversity», possessing the meaning of something general, generalized and that is why suitable to characterize both a separate thing, notion and system of things, notions of one class (Marx \& Engel, 1978). In the concrete the objects of cognition are presented as integral objects characterized by versatility, complexity and high development of the system. The abstract, in its turn, is understood as one of the defining moments of the concrete-as something partial, one-sided, incomplete (that is why defective if necessary) but at the same time real, vital representation of the concrete, separating or separated from it relatively individual entity, seeming independent moment (Ilenkov, 1984). In accordance with such characteristic, obvious, evident educational activity of a teacher and external cognitive activity of a student are considered as abstract forms of some complex human activity once appeared and developing social-historical activity of people education. In other words, the abstract is just one side, part of the whole, studied by the scientists as something perceiving, one-sided, simple and undeveloped.

\section{Results}

The concrete is usually understood as something perceptual, visible, sensible, i.e. empirical notion. The abstract in it turn is understood as something imaginative, theoretical, not connected with life and reality. This commonly accepted understanding is quite often and incorrectly used in science for description of pedagogical reality. In practice simultaneous application of commonly accepted, scientific and specific theoretical notions is just complicates researches and practitioners for whom the scientists propose their recommendations.

When carrying out the research, we came to the representation of monosystem of educational sphere as the limit of consequent generalization and combination of the achievements of pedagogical science and pedagogical practice. In the reverse process we can find an explanation for deployment of educational space and appearance of each particular pedagogical form as a result of a chain of successive, gradual differentiations of the fundamental-applied, starting from the initial, primary differentiation of biosocial unity of a person. Deep differentiations will always result in completely opposite micro- and macro certainties that complement one another to the initial whole. Then change in one area of educational sphere could occur only by changing all its other parts. Improvement of understanding of integration and differentiation processes will lead to the understanding of educational processes, alternate integration and disintegration of theory and practice, of the fundamental and the applied (Asadullin \& Teregulov, 2014).

\section{The Practical Significance of the Work}

Complex of methodological knowledge of the biosocial bases and externally-internal conditions of their interactions which are discussed in this work, laying down in the consciousness of each person as a basis scheme orienting of its life and professional activities, can effectively solve the problems of the existing and design more advanced educational practice. The results can be incorporated into the methodological basis of modern educational technology used in educational field as a whole.

\section{Discussion.}

\subsection{Basis for Reconstruction of Pedagogical Education}

If correlates the concrete with a single, contemplated thing than the purpose of theoretical study is to find common, similar features possessed by all things of the definite group. In our case the purpose is to find common features, characteristics and correlations of pedagogical activity expressed in the whole pedagogical experience. The common, as it is, means similarity observed in it. The common is abstract as it is formed only by the researcher and does not extend to the detection of significant features, allowing finding a common denominator for these objects. In such case the common is represented as partial characteristic of pedagogical reality.

That is why the process of studying starts from perception of the feature and goes to the understanding of its essence, which should be presented as the higher form of knowledge-notion.

In other words we should reproduce the system of inner connections and correlations of educational process, constituting this particular educational experience, and at the same time reveal the innovations that took place on the side of the subject. This is possible if we disclose the nature of education and reflect it in notions. Generally, fundamental knowledge should include connections and relations which are sufficient for understanding of humanity, stages of person development, essence of educational systems, ways of its development and do not possess secondary, subsidiary characteristics. The researcher should have general plan of the studied whole and 
its principle divisions, which will help to carry out the study properly creating abstractions if required and adding auxiliary branches to the general plan. During performance of such study, the notions such as theoretical and empirical in education are also become actual. They are considered as the next stage of analytical procedure by the definite characteristics of the notion existence. The specificity of theoretical reflection consists in the ability to express current educational processes, concepts and new formations in the logics of notions. The problem is not to prove the existence of nature of education-it exists while there is connection between the generations-but in identification of conceptual construction and principle of explanation, sufficiently and fully expressing the essence of education and creativity of people involved in it. Together with the content-related identification of the notions of the fundamental and the applied, it is also become necessary to determine the mechanisms of mutual transfers, arrange optimal correlations, identify measures of the required and reasonable sufficiency of the indicated categories in the development of new educational systems and processes. So the issue of abstract and concrete relation is not considered in the context of correlation of mental-perceptual, theoretical-empirical but allows identifying correlation of fundamental and applied in the structural-informative context.

There is no doubt that for studying of pedagogical notions and development of educational process, for generalization of innovative, pioneering pedagogical experience you need to have fundamental knowledge-scientific view of social-historical experience of teaching and bringing up of coming generation. It is necessary for the researcher, developing new educational practice, to hold in the mind both general and concrete knowledge. It is obvious that for the development of a new practice we need applied knowledge, which will allow us to get not only complete data about characteristics of the planned object but also about ways and structure of its development.

\subsection{The Role of Applied Knowledge in Professional Training}

Applied sciences have strongly marked orientation to the introduction of changes into the ambient reality-creation of artificial objects on the basis of knowledge about the essence and conditions of it are extending by means of applied algorithms. In some sense applied knowledge is a definite level and next stage of the development of the fundamental, cross section of its generalization. To each level of generalization that is to each fundamental corresponds the applied and not one. The next peculiarity of applied sciences is that they have pronounced technological-instrumentalization character thanks to which it could be really improved. Innovations in this area are expressed in the involvement of the set of external conditions related to genetic branching and they could be also expressed in the combinational sequence of actions and algorithmic systems of procedures. They posses data about what and how should person act, i.e. which actions, by means of what and in which order a person should perform to obtain the desired product. In other words in the applied knowledge the information is focused as an orientational basis for executive actions, so it is often considered as an instruction, recommendation or algorithm. So we can say that applied knowledge set the norms of activity and that is why its subject should know: firstly, how to do it, secondly, how the activity is technologized by the parameters determined by the characteristics of the objects. Moreover you should take into account that composition and logics of the used knowledge and actions are determined not by the quantity of the elements, composing the structure of object, but by the fact how its functions comply with the conditions of the environment.

\subsection{Peculiarities of Scientific Activity}

In the science, as in the specific cultural activity, knowledge are produced for knowledge reflecting real ambient environment and this quality is its essential assignment. Another peculiar feature of scientific activity is expressed in graduality, sequence of actions and stage-by-stage perception. Further, knowledge obtained during the research should be represented in the forms assisting for its multiplication. The abovementioned characteristics prove that fundamental knowledge in the pedagogy is closely connected with its history, with genetic presentation of educational process and reflection of the studied reality in the theory of education. So, they are connected with the pedagogical way of thinking supposing examination of interconnections of logical form of pedagogy with historically understood pedagogical reality.

The historical is primary to the logical. As it is known the logical is represented by the knowledge about existence of the object starting from its birth and till the death, separated from anything accidental and nonexistent. The logical-is consequently required elements in reflections about reality. The historical is primary as it is concrete information in relation to which we can make a conclusion. The historical describes the object in which uniform logical is composed from multiple historical because the logical is the result, and even line of results of human activity (Gretsky, 1978). For pedagogical activity the true presentation of educational process, its performance and development should be accompanied by knowledge and skills for the planning, development and management of educational systems as well as by the ways of its realization. 
Genetic character of scientific cognition leads to the necessity to detect two component parts of the objective truth: absolute (independent from the consciousness) and relative (truth uncovered partially, suitable for enrichment and specification, for independence from earlier unknown and then discovered misperceptions and so on). In other words, knowledge, being an intermediate product of people's cognitive activity, is constantly improving, developing and generalizing. In connection with this fact, the peculiarity of the fundamental research is its orientation to the generalized originality, to genetic folding and expansion of knowledge and to the specialization of logically integral presentation of the reality. Fundamental knowledge includes all previous context knowledge as one of its elements, because fundamental knowledge is the result of informative generalization of the previous knowledge (Davydov, 1972).

Nevertheless, the peculiarity of informative generalization should not be considered as a simple unity of various conclusions. It's more like gradual genetic analysis: examination of initial («basic») objective factors of development, composition of the "embryo» of the studied innovation, gradual development of which is expressed in wide diversity thanks to the examination of a large quantity of peculiarities of the environment of existence. Possessing such knowledge allows perceiving the world and at the same time representing the reality as a developing system. It's all about the level of knowledge generalization, identification of fundamental processes and corresponding knowledge, which serve as a practical reference point for people's development. However «knowledge transfer» to the sphere of solution of practical problems requires consideration of conditions of the environment where a new pedagogical object will be developed and realized (Asadullin \& Teregulov, 2011, 2012).

This is an extremely important statement. Maybe it is even necessary to treat the factor of environment conditions as the second, contrary to the first (fundamental)-wide, separate, diffusion-varied but not unified connected multitude. Together they will compose particular micro- and macro-poles of folded-expanded, generalized-individual, continuous-discrete, equal and important counter processes of educational sphere development. However each situation requires specific fundamental-applied ratio that is expressed in individual course, in new knowledge.

\subsection{Factors and Conditions for Knowledge Formation}

Finally, the structure of any of the abovementioned is formed as the derivative of fundamental-applied knowledge ratio, level and measure of expansion taken in accordance with the multiple factors of ambient environment. What does these factors of human development and principles of their coordination mean? Actually it turned out that, from the first view, in secondary and consequential processes occur «tectonic» faults and lies the essence of pedagogical innovations. Without taking into account the surrounding conditions neither pedagogical activity could be performed and neither pedagogical project could be realized.

As per the philosophical dictionary, condition as one of the categories of determinism forms the moment of the general dialectic interrelation of the world (Frolov, 2001). In the Russian dictionary by Ozhegov conditions are determined as the rules established in some sphere of life activity on the one hand and as the situation when something is happening on the other hand (Ozhegov, 2007). Although the subject of the study is something internally aroused and condition is relating to the subject external multitude of the objective world. That means that in comparison with the reason which generates some action or process, conditions compose the environment, situation where these conditions appear, exist and develop.

From psychological-pedagogical point of view, category «condition» could be treated firstly as «circumstance on which something depends», secondly as «requirement imposed by one of the parties», thirdly as «rules established in some sphere of life activity and guiding demands-situation, environment where the notions appear, exist and develop» (Rubinštejn, 1984). In particular Polonsky (2004) considers conditions as a set of variable natural, social, external and internal impacts influencing physical, moral, mental development of a person, human's behavior, education and formation of personality. Yakovleva (1991) understands pedagogical conditions as a set of measures of educational process, providing achievement by a student of professional-creative level of thinking. Andreev (1996) and Nein (1995) treat pedagogical conditions in a more wide extent: as a set of objective possibilities of content, forms, methods, instruments and material-space environment aimed at the solution of assigned tasks. Yakovlev and Yakovleva (2006) also consider the notion pedagogical conditions in wider extent and note that in relation to the subject pedagogical conditions are always external factors. Informative generalization of studies devoted to the issue of pedagogical conditions carried out by Lvov (2014) allowed him to determine four points of view: treating pedagogical conditions as circumstances, as a set of measures, as an environment, as a characteristic of the subject of pedagogical activity.

Finally we can say that the problem is-how does the examined subject develop in the cooperation of these 
difficult to understand external-internal poles. G. Hegel wrote: «When all conditions are obvious, the subject should be real and the subject itself is one of the conditions (bolded by author of the article), as initially being internal it is just some supposition» (Hegel, 1970). Let's refer to the statement of Zeldovich (1965) «Understanding of internal reasons by its external manifestations may be and is the most important, most precious and interesting in the whole science». So it is referred to generalization of some condition (or a set of conditions) in comparison with the others due to its stage-level coordination. Objective basis for the development of educational processes of generalization, folding, expansion of knowledge and etc. could appear in the education only in case of such understanding of conditions.

It is obvious that teachers who understand the laws of educational sphere and acknowledge the existence of multiple external-internal objective conditions, which could serve as reasons and as consequences, obtain the possibility to create favorable and eliminate unfavorable conditions of their activity. In such case condition should be understood as something existing independently (able to change and develop), transforming during the activity into the examined subject, which became the combination of realized secondly significant conditions. Another combination of conditions of notion successful development is provided by the environment where the object exists and operates.

\subsection{Theoretical-Methodological and Practical Side of Ambient Reality}

People cooperate with the surrounding world, with each other and wish to study the world around us. Scientists also want to understand the reality and perception of its sources is carried out in two directions: theoretical-methodological and practical. In the first direction scientists carry out intellectual work for perception of the essence and performance algorithms of the objects. In the second direction scientists search new approaches and instruments for improvement of the reality required for development of new objects. They constantly carry out scientific researches aimed to find the unified theory or the main idea which could create two flows of cognition and transformation of objects of reality. Desired methodological-theoretical provisions should explain the existing diversity of the world and unify our understanding of the evolutional development of the mater in order to create favorable conditions for living and development of a person.

It is obvious that these aspects of world cognition are closely connected. While performing practical activity, experimentation is guided by the scientific concepts. He proves or denies theoretical predictions and when he find extraordinary phenomena, he tries to explain it, forms a hypothesis for practical application of this knowledge. There are a lot of such, so called, practical scientists. Nevertheless, there a lot of, so called, thinkers, trying to unify theoretical provisions and experimental facts. But neither of the abovementioned scientists manage to create the «genealogic tree of the nature». Absence of serious generalizing studies at the level of methodology, insufficiency of productive ideas enable scientists to develop. This shows the significant role of methodological culture in the perception and improvement of the reality and educational sphere in particular.

\section{Conclusion}

It should be noted that educational sphere was not provided to our ancestors as it is, it replaced the instinctive behavior of animals, which appeared with the evolution and is transferred from one generation to another. Development of educational sphere was gradual. Education was developing together with each new generation serving as an external social phenomenon. So we can make a conclusion that development of educational practice and pedagogical science, in particular, as well as further development of their interrelation, has public-historical character.

Educational sphere, thanks to which our ancestors separated from animals and became homo sapiens, possesses objective character and its subject could not change depending on the scientist. On the other hand, educational sphere is established historically, obtaining by means of empirical development and theoretical perception of it by people, more distinct contours. In the process of its development the subject of education and educational science are also developing and methods and techniques of education are improving. Firstly the development is carried out spontaneously and latter it becomes more and more organized. Firstly comes empirical generalization which gradually develops into theoretical generalization. So we can say that teachers of the past worked with the same pedagogical whole but in another phase of its historical development. Such point of view alters the matter because we obtain the right for logical analysis of any pedagogical theory created tens and hundreds of years ago, as well as right for critical comparison of these theories with the actual image of reality, which we have nowadays, from the point of view of modern psycho-pedagogical science (Asadullin \& Teregulov, 2011, 2012).

From the very beginning, the educational work was and had always been a social, public work, which was an integral part of people's livelihoods, but unequally divided between its different participants. It was imposed by spontaneously formed-and therefore incomprehensible to them-the fundamental whole. Hence it is clear that a 
huge number of individual educational applications generally depend on this emerging fundamental whole through its direct opposite, i.e. through private, fragmented and not previously interacting independent educational activities and operations, composing now a large set of pedagogical conditions. Disadvantages of current ideas, which teachers follow in the educational process, consist in their fragmentary nature, fragmentation and linearity, in the absence of systematic perception of cognition processes and transformation of the reality in order to educate and to bring up the younger generation. And it is not so much a further problem for the educational experts as a persistent "headache" for theorists of education. The fact that the education of prospective teachers involving the study of the naturally complicating levels of movement of the objective reality is observed in various branches of science, between which people themselves have erected barriers difficult to overcome. Therefore, the efforts of scientists, educators and teachers focus on the following: justification and implementation of interdisciplinary connections; creation of comprehensive academic disciplines; search of invariants, universal means of the reality perception, and reinforcement of the results of this reflection in the external form as visual and study guides and multimedia training tools. In this direction, the scientists demand to implement various approaches: the dialectical, complex, synergistic, hermeneutical, axiological, holistic, activity, personal. But the problem is to find a common origin and ancestral branches from it.

\section{Acknowledgments}

This article was published by the state mission of the Ministry of Education and Science of Russia in 2014 under the project: «Subjective development of personality of a prospective teacher in professional activities».

\section{References}

Andreev, V. I. (2014). Pedagogical Factors Stimulating the Self-Development of Students' Multi-Dimensional Thinking in Terms of Subject-Oriented Teaching. International Education Studies, 7(7), 63-68. http://dx.doi.org/10.5539/ies.v7n7p63

Asadullin R. M., \& Teregulov, F. Sh. (2012). Space and time of the educational process. New in psychological-pedagogical researches, 2, 34-53.

Asadullin, R. M., \& Teregulov, F. Sh. (2014). Education-A new look. Siberian Education Journal, 5, 160-166.

Asadullin, R. M., \& Teregulov, F. Sh. (2011). A man as a subject of pedagogics and pedagogical anthropology. Siberian pedagogical magazine, 1, 49-64.

Davydov, V. V. (1972). Types of generalization in education. M.: Pedagogika.

Gretsky, M. N. (1983). The logical and the historical in Marx's study about social development. Philosophic sciences, 2.

Hegel's Philosophy of Nature. (1970). London: Allen \& Unwin. http://dx.doi.org/10.4324/9781315823522

Ilenkov, E. V. (1984). Dialectic logic. M.

Lvov, L. V. (2014). Theoretical basis of designing of pedagogical conditions. Innovations in education, 1, 75-92.

Marx, K., \& Engels, F. (1978). Reader (2nd ed.). W. W. Norton \& Company. http://dx.doi.org/10.4337/9781845425500.00064

Nein, A. Ya. (1995). About methodological tool of thesis research. Pedagogics, 5, 44-49.

Ozhegov, S. I. (2007). Russian dictionary: About 53000 words. M.: Oniks.

Polonsky, V. M. (2004). Education and pedagogics dictionary. M.: Vysh. shk.

Rubinštejn, S. L. (1979). Zu den philosophischen Grundlagen der Psychologie. Berlin: Volk und Wissen. http://dx.doi.org/10.1007/978-3-642-72348-3_3

Yakovlev, E. V., \& Yakovleva N. O. (2006). Pedagogical concept: Methodological aspects of construction. M. http://dx.doi.org/10.1016/j.pscr.2014.08.016

Yakovleva, N. M. (1991). Training of students for creative educational activities. Chelyabinsk: CGPI.

Zeldovich, Ya. B. (1965). Classification of elementary particles and quarks "as presented for pedestrians". Phys, 86-313. 


\section{Copyrights}

Copyright for this article is retained by the author(s), with first publication rights granted to the journal.

This is an open-access article distributed under the terms and conditions of the Creative Commons Attribution license (http://creativecommons.org/licenses/by/3.0/). 